\title{
PENGARUH PENERAPAN MODEL PEMBELAJARAN INKUIRI BERBASIS LABORATORIUM TERHADAP KEMAMPUAN PSIKOMOTORIK SISWA
}

\author{
The Effect of Inquiry-Based Laboratory Learning Model on The student Psychomotoric Ability
}

\author{
Ezha Vandia Sulawanti*, Agus Ramdani, Syamsul Bahri, I Wayan Merta \\ Program Studi Pendidikan Biologi, Jurusan Pendidikan MIPA, Fakultas Keguruan dan Ilmu Pendidikan, \\ Universitas Mataram. Jalan Majapahit No 62 Mataram, 83125, Indonesia \\ *Email:vandiasulawantiezha@gmail.com, aramdani07@unram.ac.id, syamsulsalihu@yahoo.com, \\ wayanmerta.fkip@unram.ac.id
}

Diterima: 18 Januari 2019. Disetujui: 11 Februari 2019. Dipublikasikan: 25 Februari 2019

\begin{abstract}
Abstrak.Penelitian ini bertujuan untuk mengetahui pengaruh penerapan model pembelajaran inkuiri berbasis laboratorium terhadap kemampuan psikomotorik siswa di SMA Negeri 5 Mataram Tahun Ajaran 2018/2019. Jenis penelitian ini adalah quasi experiment dengan desain post test only equivalent control group design. Populasi dalam penelitian ini yaitu seluruh peserta didik kelas XI MIA di SMA Negeri 5 Mataram tahun 2018 yang terdiri dari 6 kelas. Sampel ditentukan dengan menggunakan teknik simple random sampling dan terpilih kelas XI MIA 4 sebagai kelas kontrol dan XI MIA 5 sebagai kelas eksperimen.Instrumen yang digunakan dalam penelitian yaitu lembar observasi unjuk kerja untuk mengukur kemampuan psikomotorik peserta didik. Analisis data digunakan $t$ test separated varianspada taraf signifikansi95\%. Hasil analisis statistik menunjukkan bahwa $t_{\text {hitung }}$ lebih besar dibanding $t_{\text {tabel }}(17,21>1,99)$. Hal ini disebabkan karena model pembelajaran inkuiri berbasis laboratorium memberikan kebebasan penuh kepada peserta didik untuk melakukan percobaan layaknya ilmuwan sehingga keterampilan peserta didik dapat dioptimalkan.Hasil tersebut menunjukkan adanya perbedaan hasil belajar pada kelas yang menggunakan inkuiri berbasis laboratorium dengan yang tidak. Berdasarkan hasil tersebut dapat disimpulkan bahwa terdapat pengaruh signifikan penerapan model pembelajaran inkuiri berbasis laboratorium terhadap kemampuan psikomotorik siswa di SMA Negeri 5 Mataram tahun2018/2019.
\end{abstract}

Kata Kunci: Inkuiri Berbasis Laboratorium, Kemampuan Psikomotorik Siswa

Abstract. The purpose of this research is to know the effect of Inquiry-Based Laboratory on psychomotoric ability of students in SMA Negeri 5 Mataram in Academic Year of 2018/2019. The type of this research is a quasi esxperimental study with post test only equivalent control group design. The research population was all of the 6 classes of $11^{\text {th }}$ grade students. XI-MIA 4 (as a control class) and XI MIA 5 (as an experiment class) was choosen by using simple random sampling technique. The data was collected by using performance observation sheet to assess psychomotoric ability of students. The data analysis technique was t-test with $95 \%$ of significance level. Statistic analysis result showed that $t_{\text {value }}>t_{\text {table }}(17,21>1,99)$. This is because Inquiry-Based Laboratory let students do experimental study freely like a scientist so that students skill can be optimized. This result indicates that psychomotoric ability of student in a treatment class is significantly higher than students in control class. It is concluded that Inquiry-Based Laboratory learning model is significantly better to increase psychomotoric ability of students.

Keywords: Inquiry-Based Laboratory, Psychomotoric Ability

\section{PENDAHULUAN}

Peraturan Pemerintah Nomor 13 tahun 2015 tentang Standar Nasional Pendidikan pasal 1 ayat 19 menyatakan bahwa pembelajaran adalah proses interaksi antara peserta didik dengan pendidik dan sumber belajar pada suatu lingkungan belajar. Salah satu bentuk pembelajaran disekolah adalah pembelajaran biologi, dimana pembelajaran bilogi merupakan bidang yang mengkaji fakta empiris yang ada di alam, sehingga untuk mempelajarinya dibutuhkan suatu pengkajian laboratorium yang di desain sebagai miniatur alam [27]. Salah satu bagian dari pembelajaran biologi adalah pembelajaran eksperimen. Hal tersebut berarti bahwa pembelajaran biologi akan semakin baik bila ditunjang dengan percobaan-percobaan yang berkualitas.

Proses pembelajaran sains akan bermakna jika proses pembelajaran tersebut sesuai dengan hakekat sains, yang berarti bahwa belajar tidak cukup hanya melalui kumpulan fakta, prinsipprinsip, hukum-hukum, maupun teori, tetapi juga menyangkut bagaimana proses pengetahuan itu diperoleh. Belajar bermakna dapat mengakibatkan peningkatan dan modifikasi pengetahuan yang sebelumnya sudah ada dan bergantung pada pengalaman seseorang, hal tersebut dianggap bagian penting dari pengajaran dan pembelajaran sains [21]. Guru harus yakin bahwa siswa benar-benar terbantu untuk mempelajari materi pelajaran dan keterampilan yang dituntut dalam kurikulum berdasarkan apa yang telah dipelajari sebelumnya 
dan mempersiapkan cara untuk menghadapi tantangan yang akan datang [37].

Pada kenyataannya kebebasan siswa

dibatasi oleh instruksi guru yang yang mengakibatkan pembelajaran menjadi tidak bermakna, keterampilan rendah, siswa sering memanipulasi data dengan tujuan agar tidak melenceng dari penjelasan yang telah diberikan guru [49]. Masih banyak siswa belajar hanya menghafal konsep-konsep, mencatat apa yang diceramahkan guru, pasif, dan jarang menggunakan pengetahuan awal sebagai dasar perencanaan pembelajaran [49]. Hal tersebut mengakibatkan pembelajaran menjadi tidak bermakna dan siswa cenderung cepat lupa terhadap materi yang telah disampaikan sebelumnya.

Salah satu upaya yang dapat dilakukan agar pembelajaran menjadi lebih bermakna dan keterampilan siswa dapat dioptimalkan adalah melalui kegiatan eksperimen atau laboratorium real dimana semua alat dan bahan yang digunakan untuk keperluan praktikum benar-benar nyata (bisa dipegang dan dilihat). Siswa dapat meningkatkan keterampilan psikomotoriknya, misalnya belajar memasang, menggunakan, serta melibatkan semua inderanya seperti indera penglihatan, pendengaran, perasaan, penciuman, dan peraba [31]. Diharapkan dengan adanya laboratorium real ini keterampilan serta pengetahuan siswa dapat dioptimalkan.

Pada kenyataannya model eksperimen yang banyak digunakan di sekolah adalah eksperimen tradisional/ verifikasi, dimana model pembelajaran ini belum mampu secara optimal meningkatkan keterampilan siswa. LKS yang digunakan adalah LKS terstruktur (cookbook recipe experiment) di mana langkah-langkah praktikum telah tersedia dengan rinci, jelas dan terstruktur [40]. SMAN 5 Mataram merupakan salah satu sekolah yang termasuk kedalam kategori sekolah favorit yang berada di Mataram. Berdasarkan hasil observasi yang telah dilakukan pada bulan Maret 2018 di SMAN 5 Mataram, proses pembelajaran biologi tergolong baik karena sudah menerapkan kurikulum 2013 disetiap pembelajarannya, akan tetapi praktikum yang diterapkan masih bersifat verifikasi/ resep, praktikum dari tahun ke tahun selalu monoton, dan LKS yang digunakan adalah LKS terstruktur.

Model eksperimen verifikasi resep menjadikan siswa pasif sehingga tingkat keterlibatan siswa rendah [35]. Selain itu model eksperimen diatas memiliki tuntutan kognitif yang rendah dan tidak optimal dalam meningkatkan keterampilan berpikir kreatif siswa dalam memecahkan berbagai macam masalah [41].

Memasuki abad XXI, dunia semakin mengglobal dengan perkembangan teknologi dan pengetahuan yang begitu pesat. Perkembangan yang begitu pesat ini menuntut lembaga pendidikan untuk melakukan reformasi dalam rangka pembangunan SDM yang memiliki kecakapan intelektual dan keterampilan tinggi agar bisa bersaing [1]. Tercantum dalam Permendiknas No. 64 Tahun 2013 bahwa salah satu tujuan pembelajaran sains khususnya biologi untuk SMA adalah memahami ruang lingkup biologi dan aplikasinya di era abad XXI. Pemberlakuan kurikulum 2013 ditujukan agar kebutuhan dunia pendidikan selaras dengan kebutuhan abad 21.

Untuk mengembangkan keterampilan yang dibutuhkan siswa pada abad XXI, diperlukan suatu model pembelajaran yang berbasis pada penyelidikan ilmiah, dan siswa diberikan kebebasan dalam melaksanakan penyelidikan ilmiah tersebut. Salah satu model pembelajaran yang mampu mewujudkan hal tersebut adalah model pembelajaran inkuiri berbasis laboratorium. Inkuiri berbasis laboratorium dapat mengembangkan keterampilan dasar yang dibutuhkan siswa pada abad XXI, siswa aktif berpartisipasi, dan bekerja layaknya seorang ilmuan [16]. Inkuri berbasis laboratorium tidak terbatas di dalam laboratorium saja melainkan lingkungan luar dapat dijadikan wahana pembelajaran.

Berdasarkan uraian di atas, peneliti merasa perlu untuk melakukan penelitian dengan judul: "Pengaruh Penerapan Model Pembelajaran Inkuiri Berbasis Laboratorium Terhadap Kemampuan Psikomotorik Siswa SMA Negeri 5 Mataram Tahun Ajaran 2018/2019.

\section{METODOLOGI PENELITIAN}

Penelitian dilaksanakan pada pembelajaran semester ganjil tahun ajaran 2018/2019. Pengambilan data dilaksanakan dari bulan Agustus sampai September 2018. Adapun tempat penelitian yaitu di SMA Negeri 5 Mataram.

Jenis penelitian yang digunakan dalam penelitian ini yaitu quasi experimental research atau eksperimen semu dengan pendekatan kuantitatif deskriptif. Desain penelitian yang digunakan dalam penelitian ini yaitu post test equivalent control 
group design. Populasi dalam penelitian ini yaitu seluruh peserta didik kelas XI MIA di SMA Negeri 5 Mataram yang terdiri dari 6 kelas yaitu XI MIA 1 sampai XI MIA 6. Teknik pengambilan sampel yang digunakan dalam penelitian ini yaitu simple random sampling sehingga diperoleh kelas XI MIA 4 sebagai kelas kontrol dan kelas XI MIA 5 sebagai kelas eksperimen.

Instrumen yang digunakan dalam penelitian in adalah lembar observasi kinerja atau unjuk kerja (performance) yang terdiri dari 14 item penilaian yang menggunakan skala likert 1-4. Data kemampuan psikomotorik siswa dianalisis dengan uji t separated varians.

\section{HASIL DAN PEMBAHASAN}

Perbandingan rata- rata kemampuan psikomotorik siswa kelas eksperimen yang menerapkan model pembelajaran inkuiri berbasis laboratorium dengan kelas kontrol yang menerapkan model pembelajaran guru mata pelajaran biologi disekolah yakni kooperatif learning dapat dilihat pada Gambar 1.

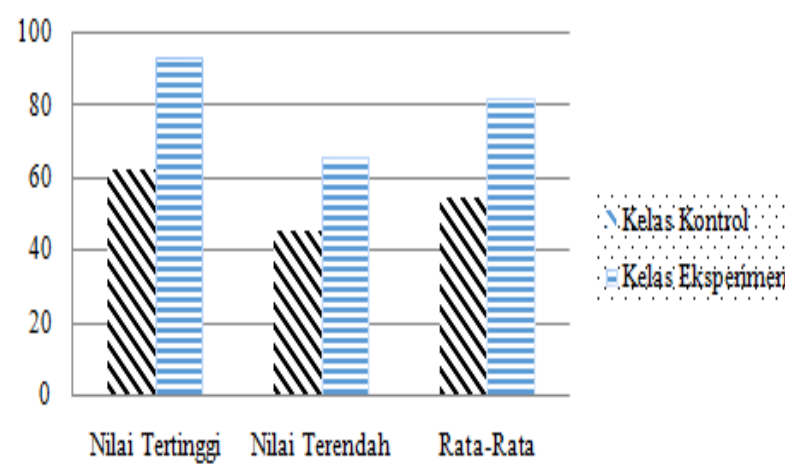

Diagram 4.1. Diagram kemampuan psikomotorik siswa pada kelas eksperimen dan kelas kontrol

Berdasarkan data tersebut, rerata nilai yang diperoleh kelas eksperimen lebih tinggi dibandingkan dengan kelas kontrol yakni pada kelas eksperimen diperoleh rerata 81,04 sedangkan kelas kontrol hanya memperoleh rerata sebesar 54,28.

Analisis kemampuan psikomotorik peserta didik dengan menggunakan uji t separated varians diperoleh hasil bahwa thitung lebih besar dibanding $t_{\text {tabel }}(17,21>1,99)$, sehingga $H_{0}$ ditolak dan $H_{a}$ diterima. Hal tersebut menunjukkan bahwa terdapat pengaruh signifikan dari penerapan model pembelajaran inkuiri berbasis laboratorium terhadap kemampuan psikomotorik siswa SMAN 5 MataramTahun Ajaran 2018/2019. Hal ini sejalan dengan hasil penelitian sebelumnya [21,29].

Model pembelajaran inkuiri berbasis laboratorium ini memiliki pengaruh positif terhadap kemampuan psikomotorik siswa karena model pembelajaran ini menuntut siswa untuk terlibat secara langsung tanpa ada perwakilan, memberikan peserta didik kesempatan untuk memecahkan masalah yang ada dengan memanfaatkan lingkungan sekitarnya dalam menemukan jawaban, karena sistem dalam model pembelajaran inkuiri berbasis laboratorium ini individu bekerja layaknya ilmuan, masing-masing peserta didik bebas melakukan percobaan yang mereka inginkan tanpa terbatas dari instruksi guru dan perintah teman. Model pembelajaran inkuiri berbasis laboratorium praktikumnya didasarkan pada partisipasi aktif siswa dalam proses pengumpulan data, analisis fakta, meningkatkan keterampilan memecahkan masalah dan memiliki sikap positif terhadap sains [17].

Melalui langkah-langkah yang diterapkan dalam model pembelajaran inkuiri berbasis laboratorium, peserta didik mampu mengembangkan keterampilan yang dimilikinya secara optimal. Model pembelajaran inkuiri berbasis laboratorium memberikan pengaruh positif pada pembelajaran siswa karena dalam prosesnya siswa diajak untuk bekerja seperti seorang imluwan, memberikan siswa pengalaman-pengalaman ilmiah, membuat siswa lebih mudah memahami materi dan dapat meningkatkan keterampilan psikomotorik siswa.

Perbedaan kemampuan psikomotorik siswa pada kelas eksperimen dan kelas kontrol disebabkan karena model pembelajaran yang diterapkan guru. Pada kelas kontrol yang menerapkan model pembelajaran guru di sekolah (kooperatif learning) kemampuan psikomotorik seperti perumusan masalah, perumusan hipotesis, perancangan percobaan, analisis data dan pengujian kebenaran hipotesis tidak dioptimalkan. Hal tersebut yang menyebabkan rerata nilai psikomotorik siswa pada kelas kontrol rendah. Sedangkan pada kelas eksperimen yang menerapkan model pembelajaran inkuiri berbasis laboratorium banyak kemampuan psikomotorik yang dicapai dan dioptimalkan sehingga rerata nilai psikomorik pada siswa kelas eksperimen lebih tinggi dibandingkan dengan kelas kontrol.

Selain itu model pembelajaran inkuiri berbasis laboratorium ini berpengaruh positif terhadap kemampuan psikomotorik siswa karena model ini melibatkan siswa melakukan eksperimen dengan benda-benda konkret. Hal tersebut tidak hanya mengenalkan konsep ilmu pengetahuan tetapi juga meningkatkan keterampilan proses sains, berpikir kreatif, kemampuan memecahkan masalah, dan metode ilmiah [21]. Model pembelajaran inkuiri berbasis laboratorium merupakan suatu rangkaian pembelajaran yang melibatkan secara maksimal 
kemampuan siswa untuk menemukan dan menyelidiki secara logis, sistematis, analitis, dan kritis, sehingga penemuan dapat dirumuskan dengan percaya diri [36]. Pembelajaran berbasis inkuiri laboratorium menekankan pada aktivitas dalam membantu siswa belajar dan memahami proses dan keterampilan berpikir layaknya ilmuan dan memahami karakteristik penelitian ilmiah [16]. Oleh karena itu model pembelajaran ini baik diterapkan untuk meningkatkan kemampuan psikomotorik siswa secara berkelanjut atau secara terus- menerus untuk membiasakan siswa melakukan eksperimen secara mandiri.

Berdasarkan hasil penelitian pada proses pembelajaran berlangsung kelas eksperimen terlihat lebih aktif dan antusias dibandingkan dengan kelas kontrol pada saat melakukan percobaan, hal tersebut dikarenakan kelas eksperimen diberikan kebebasan untuk merancang, memilih dan membuat desain percobaan sesuai dengan keinginan dan berkaitan dengan lingkungan sekitar yang biasa dijumpai sehari- hari serta tentunya memperhatikan tujuan pembelajaran. Keterlibatan siswa secara aktif baik fisik maupun mental dalam kegiatan labolatorium akan berpengaruh terhadap pembentukan pola tindakan siswa yang selalu didasarkan pada hal-hal yang bersifat ilmiah, dengan memperlakukan siswa layaknya ilmuwan dalam kegiatan pembelajaran sains [50].

Selain itu LKS yang diberikan oleh guru pada kelas eksperimen menuntut peserta didik untuk mencari permasalahan yang ada disekitar yang sering mereka jumpai, dengan permasalahan tersebut diharapkan peserta didik dapat merancang dan mendesain percobaan secara mandiri, berhipotesis dan melakukan uji kebenaran terhadap hipotesisnya, menganalisis data dan sebagainya secara mandiri, sehingga kegiatan psikomotoriknya lebih dioptimalkan. Sedangkan pada peserta didik kelas kontrol terlihat beberapa siswa yang aktif dan sebagian besar siswanya menunggu di meja masingmasing, karena kegiatan siswa hanya terfokus pada instruksi guru dan dapat diwakilkan oleh beberapa siswa saja. Model eksperimen verifikasi memiliki tuntutan kognitif yang rendah dan tidak optimal dalam meningkatkan keterampilan berpikir kreatif siswa dalam memecahkan berbagai macam masalah [41].

Jika model pembelajaran inkuiri berbasis laboratorium ini terus dilakukan, maka akan terbentuk sikap ilmiah siswa, jujur, kerja keras, tekun dan sikap positif lainnya, karena pada model pembelajaran inkuiri berbasis laboratorium ini siswa tidak dapat memanipulasi data, yang berarti data yang disajikan adalah benar-benar hasil yang didapatkan oleh peserta didik karena peserta didik sendirilah yang melakukan, mendesain dan mendapatkan hasil, menganalisis secara mandiri. Hal tersebut sesuai dengan tagihan pada kurikulum 2013 yakni penilaian dilihat dari 3 ranah yakni kognitif, psikomotorik,dan apektif.

\section{KESIMPULAN DAN SARAN}

Hasil penelitian menunjukkan bahwa, penerapan model pembelajaran inkuiri berbasis laboratorium berpengaruh terhadap kemampuan psikomotorik siswa SMAN 5 Mataram Tahun Ajaran 2018/ 2019.

Model pembelajaran inkuiri berbasis laboratorium dapat digunakan bagi pendidik dalam memilih model pembelajaran yang akan digunakan dalam pembelajaran, karena model pembelajaran inkuiri berbasis laboratorium dapat meningkatkan kemampuan psikomotorik siswa. Dalam penerapan model pembelajaran inkuiri berbasis laboratorium harus memperhatikan alokasi waktu dan kondisi peserta didik sehingga diperoleh hasil yang optimal. Langkah-langkah dalam inkuiri laboratorium juga harus diajarkan secara perlahan dan secara terus menerus pada peserta didik sehingga peserta didik dapat terbiasa untuk merumuskan masalah, berhipotesis, melakukan percobaan, dan mencari informasi secara mandiri.

Penerapan model pembelajaran inkuiri berbasis laboratorium yang dilakukan pada penelitian ini hanya terbatas pada KD 3.2, KD 4.2, KD 3.3 dan KD 4.3 mengenai transport lintas membran dan struktur dan fungsi jaringan pada tumbuhan. Oleh karena itu, perlu dilakukan penelitian lebih lanjut dengan materi dan KD yang berbeda dan sesuai dengan karakteristik model pembelajaran inkuiri berbasis laboratorium ini serta variabel yang lebih bervariasi.

\section{DAFTAR PUSTAKA}

[1] Alviani, Viki. 2015. Penerapan Bounded Inquiry Laboratory Untuk Meningkatkan Keterampilan Proses Sains Peserta Didik Kelas XI MIA 2 SMA N 1 Sukoharjo. JurnalBio-Pedagogi.Vol.4. No. 2: Hal 5 9.

[2] Anwar, Prabu Mangkunegara. 2009. Manajemen Sumber Daya Manusia. Bandung: PT. Remaja Rosdakarya. 
[3] Ardani, R. dan Suprapto, N.2014. Pengaruh Model Pembelajaran Guided InquiryBerbasis Eksperimen Terhadap Keterampilan Berpikir Kritis Siswa Pada Materi Fluida Statis Di SMA Negeri 1 Gedangan, Jurnal Inovasi Pendidikan Fisika Vol 1 No. 3: Hal. 167-173.

[4] Arifin, Zaenal. 2017. Mengembangkan Instrumen Pengukur Critical Thinking Skills Siswapada Pembelajaran Matematika Abad 21. Jurnal Theorems (The Original Research of Mathematics). Vol. 1 No. 2: Hal. 92-100.

[5] Arikunto,S. 2013. Prosedur Penelitian Suatu Pendekatan Praktik. Jakarta: Rineka Cipta.

[6] Depdiknas. 2003. Sistem Penilaian Kelas $S D, \quad S M P, \quad S M A$, dan SMK. Jakarta: DirektoratJenderal Pendidikan Dasardan Menengah Kependidikan.

[7] Ernita, Nevi. 2013.Penerapan Model Pembelajaran Inkuiri Terbimbing Berbasis Laboratorium dan Pengaruhnya Terhadap Hasil Belajar Fisika Peserta Didik SMA Negeri 8 Mataram. Jurnal Ilmiah Pendidikan Fisika "Lensa" Vol. 1 No. 2: 103-108.

[8] Genesee,Fred dan John A.Upshur. 1997. Classroom- Based Evaluation in Second Languange Education. Cambridge: Cambridge University Press

[9] Hernita, Resty. 2016. Pengembangan Modul Berbasis Bounded Inquiry

Laboratory (Lab) Untuk Meningkatkan Literasi Sains Dimensi Proses Pada Materi Sistem Pencernaan Kelas XI. Jurnal InkuiriVol 5, No. 2: Hal 94-107.

[10]Hodson, Michael. 2013. The Intermediary Organisation of Low Carbon Cities: A Comparative Analysis of Transitions in Greater London and Greater Manchester. Urban Studies Journal Limited Vol. 50 No. 7: Hal 1403-1422.

[11] Ibnu, Hajar. 1999. Dasar- Dasar Metodologi Penelitian Kuantitatif dalam Pendidikan. Jakarta: Raja Grafindo Persada.

[12] Irnaningtyas dan Istiadi Yossa. 2014. Biologi. Jakarta: Erlangga.

[13] Istarani. 2011. 58 Model Pembelajaran Inovatif (Referensi Guru Dalam Menentukan Model Pembelajaran). Medan: Media Persada.

[14] Jufri, A.W. 2013. Belajar dan Pembelajaran Sains. Lombok Barat: Arga Puji Press.

[15] Ketpichainarong W, Panijpan B, Ruenwongsa P. 2010. Enhanced Learning Of Biotechnology Student by an InquiryBased Cellulase Laboratory.Inter.J.
Environmental\&Science Education Vol.5 No 4: Ha 169-187.

[16] Khan, M. S. 2011. Effect of inkuiri method on achievement of students in chemistry at secondary level.International Journal Of AcademicResearch. Vol. 11 No.3:Hal955-959.

[17] Koray, Ö., \& Köksal, M. S. 2009. The effect of creative and critical thinking based laboratory applications on creative and logical thinking abilities of prospective teachers. Asia-Pacific Forum on Science Learning and Teaching Journal.Vol 10, No. 2:Hal 1-13.

[18] Kountur, Ronny. 2009. Metode Penelitian Untuk Penulisan Skripsi dan Tesis Edisi Revisi. Jakarta: Buana Printing.

[19] Kunandar. 2013. Penilaian Autentik (Penilaian Hasil Belajar Peserta Didik Berdasarkan Kurikulum 2013). Jakarta: Raja Grafindo Persada.

Maretasari.2012. Penerapan Model Pembelajaran Inkuiri Terbimbing Berbasis Laboratorium Untuk Meningkatkan Hasil Belajar Dan Sikap Ilmiah Siswa.Unnes physics education journal.Vol. 1 No. 2 : Hal 28-31.

[21] Maryam, Neneng.2017.Implementasi Model Inkuiri Berbasis Laboratorium Terhadap Perubahan Konseptual Siswa SMA Pada Konsep Fotosintesis.Jurnal Edusains. Vol. 9. No. 01: Hal 12-13.

[22] Maya, Prima. 2016. Pengembangan Modul Berbasis Guided Inquiry Laboratory Untuk Meningkatkan LiterasiSains Dimensi Proses Materi Sistem Pencernaan Pada Kelas XI. Jurnal Inkuiri. Vol 5. No. 2: Hal 2-4.

[23] Meta. 2012. Inkuiri Laboratorium. https://smartstudentblog.wordpress.com/2 012/05/31/inkuiri-laboratorium/, diakses tanggal 25 Maret 2018 pukul 22.07 WITA.

[24] Mulyasana, D. 2011. Pendidikan Bermutu dan Berdaya Saing. Bandung: Remaja Rosdakarya.

[25] Muniarti, Eka Noviyanti. 2011. Metode Praktikum Untuk Melatih Kemampuan Psikomotorik Siswa Pada Materi Tekanan dan Getaran di Kelas VIII SMP N 1 Kayuagung. diaskses pada10 Maret 2018.

[26] Muslich, Mansur. 2011. Pendidikan Karakter Menjawab Tantangan Krisis Multidimensional. Jakarta: PT Bumi Aksara. 
[27] Muzakkir. 2015. Pengaruh Pelaksanaan Praktikum Inkuiri Berbasis Laboratorium Virtual Terhadap Peningkatan Motivasi Dan Kreativitas Siswa. Jurnal Pendidikan Sains Indonesia. Vol. 03. No.01 : Hal 125134.

[28] Nakhleh MB, Polles J,Malinae.2002. Learning Chemistry in a Laboratory Environment: In J.K.

[29] Ocktaviana, Rina. 2013. Penggunaan Pendekatan Inkuiri Berbasis LaboratoriumPada Konsep Sistem Peredaran Darah Untuk Meningkatkan Proses dan Hasil Belajar Siswa SMA Negeri 2 Banjarbaru. Jurnal Wahana-Bio Vol.10. No 3 : Hal 21-36.

[30] Ormrod, J. E. 2003. Application Of Eigenvalues And Eigenvectors And Diagonalization To Environmental Science .Educational Psychology: Developing Learners. Merrill Prentice Hall. Vol. 2 No. 4: Hal 106-109.

[31] Perdanawati, Eska. 2017. Perbedaan Model Pembelajaran Modified Free Inquiry (MFI) Berbasis Laboratorium Riil Dengan Virtual Pada Pokok Bahasan Laju Reaksi Terhadap Hasil Belajar Kimia Siswa SMAN 1 Pasangkayu. Jurnal Mitra Sains. Vol. 5 No. 1 : Hal 26-35.

[32] Popham, W. James. 1995. ClaaroomAssessment What Teacher Need to Know. Boston: Allyn and Bacon.

[33] Prawirohartono, Slamet. 2016. Konsep dan Penerapan Biologi. Jakarta: PT Bumi Aksara.

[34] Purwanto, dkk. 2013. Analisis Kemampuan Inkuiri dan Hasil Belajar Siswa Sekolah Menengah Pertama melalui Model Pembelajaran berbasis Model Hierarki Of Inquiry. Prosiding Pertemuan Ilmiah XXVII HFI Jateng \& DIY, Solo, 23 Maret 2013. ISSN : 0853-0823.
[35] Rahmawati. 2017. Inquiry-Based Laboratory Activities On Drugs Analysis ForHigh School Chemistry Learning. Journal of Physics International Conference on Mathematics and Science Education (ICMScE). Conf. Series 895.

[36] Ratnasari, Jufita. (2016). Penerapan Model Pembelajaran Inkuiri Terbimbing Berbasis Kegiatan Laboratorium Untuk Meningkatkan Hasil Belajar Siswa Pada Materi Elastisitas Kelas X SMA Negeri 2 Sidoarjo. Jurnal Inovasi Pendidikan Fisika (JIPF) Vol. 05 No. 02: Hal 3-4.

[37] Rustam, Agus Ramdani,Prapti Sendijana (2017).Pengaruh Model Pembelajaran Process Oriented Guided Inquiry Learning (POGIL) terhadap Pemahaman Konsep IPA, Keterampilan Proses Sains dan Kemampuan Berfikir Kritis Siswa SMP Negeri 3 Pringgabaya Lombok Timur. Jurnal Penelitian Pendidikan IPA (JPPIPA).

[38] Sudrajat, Akhmad. 2008. Pembelajaran dan Penilaian Psikomotorik (Depdiknas). (Blog di WordPress.com. The Responsive Theme, diakses 4 April 2018.)

[39] Sugiyono. 2013. Metode Penelitian Pendidikan, Pendekatan Kuantitatif, Kualitatif, dan $R \& D$. Bandung: Alfabeta.

[40]Sugiyono. 2017. Metode Penelitian Pendidikan, Pendekatan Kuantitatif, Kualitatif, dan $R$ $\& D$. Bandung: Alfabeta.

[41]Suma, K. 2005. Efektivitas kegiatan laboratorium konstruktivis dalam meningkatkan penguasaan konsep-konsep arus searah mahasiswa calon guru. Jurnal Pendidikan dan Pengajaran. Vol. 38 No. 2 : Hal 159 - 171.

[42]Sutami, Evi. 2014. Hubungan Antara Penilaian Kinerja Dan Hasil Belajar Pada Konsep Cahaya Dengan Metode Ekperimen. Jakarta: Universitas Islam Negeri Syarif Hidayatulah.

[43]Upi. 2011. Kemampuan Psikomotorik Siswa SMA Kelas XII dalam Praktikum Strukturtumbuhan.http://repository.upi.Edu/ operator/upload/s_d035 0606655 chapter2. pdf, diakses pada 29 maret 2018. 
[44]Vajoczki et al. 2011. Inquiry Learning: Level, Discipline, Class Size, What Matters?. International Journal for the Scholarship of Teaching and Learning. Vol. 5. No. 1: Hal 23-26.

[45]Wallace CS, Tsoi MY, Calkin J, \& Darley M. 2003. Learning from inquiry-based aboratories in non major biology: An interpretive study of the relationships among inquiry experience, epistemologies, and conceptual growth. Journal of Research in Science Teaching Vol 5. No. 40: Hal 9861024 .

[46] Wenning, C. J. 2006. Levels Of Inquiry : Hierarchies Of Pedagogical practice and Inquiry Procesess. Journal of Physics Teacher Education Online : Http: www. Phy.ilstu.edu. 23 Maret 2018.

[47] Wenning, C. J. 2010. Levels of inquiry: Using inquiry spectrum learning sequences to teach science. Journal Physics Teacher of Education. Vol 5 No 4 : Hal 11-19.

[48] Widoyoko, S. Eko Putro. 2009. Evaluasi Program Pembelajaran. Yogyakarta: Pustaka Pelajar.

[49] Wirtha, I. M. \& Rapi N. K. 2008. Pengaruh Model Pembelajaran dan Penalaran Formal Terhadap Penguasaan Konsep Fisika Dan Sikap Ilmiah Siswa SMA Negeri 4 Singaraja. Jurnal Penelitian dan Pengembangan Pendidikan Lembaga Penelitian Undiksha. Vol. No. 12: Hal 1529.

[50] Wiyanto. 2006. Pengembangan kemampuan merancang kegiatan laboratorium fisika berbasis inkuiri bagi mahasiswa calon guru. Jurnal Pendidikan dan Pengajaran IKIP Negeri Singaraja. Vol 2. No. 3 : Hal. 422439.

[51] Yaumi, Muhammad. 2014. Prinsip-Prinsip Desain Pembelajaran. Jakarta: Kencana. 